This is the peer reviewed version of the following article:Uddin, Z, Woznowski-Vu, A, Flegg, D, Aternali, A, Wickens, R, Wideman, TH. Evaluating the novel added value of neurophysiologieal pain sensitivity within the fear-avoidance model of pain. Eur J Pain. 2019; 23 : 1957-972. which has been published in final form at https://doi.org/10.1002/ejp.1364 This article may be used for non-commercial

purposes in accordance with Wiley Terms and Conditions for Use of Self-Archived Versions."

WILEY EJP

\title{
Evaluating the novel added value of neurophysiological pain sensitivity within the fear-avoidance model of pain
}

\section{Zakir Uddin | Arthur Woznowski-Vu | Daniel Flegg | Andrea Aternali}

\section{Rebekah Wickens | Timothy H. Wideman}

School of Physical and Occupational

Therapy, McGill University, Montreal, QC

2 Canada

\section{Correspondence}

Timothy H. Wideman, School of Physical and Occupational Therapy, McGill

University, Montreal, Quebec, Canada.

Email: timothy.wideman@mcgill.ca

\section{Funding information}

This study was generously supported by research funds from the following organizations: Louise and Alan Edwards

Foundation, Quebec Pain Research Network, Canadian Musculoskeletal Rehab Research Network, Institut de recherche Robert-Sauvé en santé et en sécurité du travail (IRSST) and the Canadian Institutes for Health Research. Funders had no influence on study methodology, manuscript preparation or publication decisions.

\begin{abstract}
Background: The fear-avoidance model (FAM) is a leading theoretical paradigm for explaining persistent pain following musculoskeletal injury. The model suggests that as injuries heal, pain-related outcomes are increasingly determined by psychological, rather than physiological factors. Increasing literature, however, suggests that neurophysiological processes related to pain sensitivity also play an important role in chronicity. To date, there has been limited research that has specifically explored the role of pain sensitivity within the FAM. This study addresses this gap by evaluating whether clinical measures of pain sensitivity help explain FAM-related outcomes, beyond model-relevant psychological predictors.
\end{abstract}

Methods: The study sample consisted of 80 adults with chronic and widespread musculoskeletal pain. Participants completed a single testing session that included measures of all of the major constructs of the FAM, including pain catastrophizing, pain-related fear, activity avoidance (self-report and functional measures), pain-related disability, depression and pain severity, as well as a battery of quantitative sensory testing that included measures of pressure pain threshold and temporal summation of mechanical pain across eight body sites.

Results: A series of hierarchical regression analyses revealed that after controlling for the psychological predictors of the FAM, indices of pain sensitivity significantly predicted 4 of the 5 FAM-related outcomes $(p<0.05)$. Depression was the only outcome not significantly predicted by pain sensitivity. Interestingly, measures of pain sensitivity, but not FAM psychological factors, predicted the functional measure of activity avoidance.

Conclusions: These findings provide further evidence for the importance of neurophysiological factors within the FAM and have important clinical and theoretical implications.

Significance: This study provides evidence for the unique and added value of neurophysiological factors within the Fear Avoidance Model of pain and for the importance of integrating both sensory and psychological factors within both theoretical paradigms and clinical management strategies. 


\section{INTRODUCTION}

The fear-avoidance model (FAM) of pain is one of the leading theoretical paradigms for explaining why pain, and its negative sequela, persist following musculoskeletal injury (Vlaeyen, Kole-Snijders, Boeren, \& Eek, 1995; Vlaeyen \& Linton, 2000). The model suggests that as injuries heal, painrelated outcomes are increasingly determined by psychological, rather than physiological factors (Leeuw et al., 2007; Vlaeyen, Kole-Snijders, Rotteveel, Ruesink, \& Heuts, 1995; Vlaeyen \& Linton, 2000). Specifically, the model posits that elevated levels of pain catastrophizing and pain-related fear contribute to several negative outcomes, including increased activity avoidance, depressive symptoms, disability and pain severity. The model has inspired considerable research that has helped establish psychological factors as key predictors of chronicity and theoretically driven clinical management strategies (Crombez, Eccleston, Damme, Vlaeyen, \& Karoly, 2012; Kroska, 2016; Parr et al., 2012; Vlaeyen \& Linton, 2012).

Despite its important contributions, the FAM does not fully account for the growing evidence supporting the role of nervous system sensitivity in perpetuating pain and painrelated outcomes (Wideman et al., 2013). Previous work has shown that neurophysiological changes in the nervous system can have a net sensitizing effect that contribute to more intense, widespread and persistent pain symptoms (Woolf, 2004, 2011; Woolf \& Salter, 2000). Among people with chronic musculoskeletal pain, neurophysiological sensitization is linked to worse clinical symptoms and reduced prognosis for recovery (Goodin et al., 2014; Lim, Sterling, Stone, \& Vicenzino, 2011; Maixner, Fillingim, Sigurdsson, Kincaid, \& Silva, 1998; Mallen, Peat, Thomas, Dunn, \& Croft, 2007; Woolf, 2011). Within clinical research, increased pain sensitivity is commonly measured via quantitative sensory testing (QST) (Arendt-Nielsen \& Yarnitsky, 2009; Matos et al., 2011; Neziri et al., 2012; Rolke, Baron et al., 2006; Yarnitsky \& Granot, 2006). QST is an indirect, psychophysical proxy of neurophysiological sensitization and consists of evaluating subjective responses to standardized sensory stimuli (e.g., blunt pressure and pinprick). Previous work has shown a partially overlapping relationship between QST measures and FAM-related psychological factors (Finan et al., 2013; Hübscher et al., 2013; Mason, O'Neill, Lunt, Jones, \& McBeth, 2018; Uddin, MacDermid, Moro, Galea, \& Gross, 2016; Wallin, Liedberg, Börsbo, \& Gerdle, 2012; Wideman et al., 2014). Different QST measures of pain sensitivity have also been linked to neurophysiological indicators of nervous system sensitization and clinical pain-related outcomes (Binderup, Arendt-Nielsen, \& Madeleine, 2010; Bishop, Horn, \& George, 2011; Graven-Nielsen \& Arendt-Nielsen, 2010; Lim et al., 2011; Neziri et al., 2012; Staud, Robinson, \& Price, 2007; Tampin, Slater, Hall, Lee, \& Kathryn, 2012;
Uddin \& MacDermid, 2016; Uddin, MacDermid, Galea, Gross, \& Pierrynowski, 2014).

To date, there has been limited research that specifically combines these two lines of work to explore the role that increased pain sensitivity plays in the FAM. Recent work has highlighted the need for this type of research to help determine whether neurophysiological processes should be further integrated within the FAM and to help inform model-driven approaches to clinical management (Wideman et al., 2013). One recent study by Pedler, Kamper, Maujean, \& Sterling (2018) explored these relationships among people with whiplash-related injuries. This study showed that QST measures of pain sensitivity offer novel predictive value in determining self-report measures of pain and pain-related disability, even after controlling for the psychological predictors of the FAM. However, there has been limited work exploring the predictive value of pain sensitivity within other clinical populations and in relation to each of the FAM-related outcomes. This study aimed to help fill these gaps by determining whether different QST measures of pain sensitivity contribute novel predictive value, beyond FAM-related psychological predictors, in determining measures of avoidance, depression, disability and pain severity. We hypothesized that QST measures of pain sensitivity will contribute novel predictive value when integrated within the FAM.

\section{METHODS}

\section{1 | Participants}

This study included participants fulfilling the following eligibility criteria: age 18 years or older, daily pain persisting for longer than 3 months that was associated with musculoskeletal symptoms (e.g., muscle pain and joint pain), medically stable and no contraindications to physical activity. Participants were recruited from wait-lists to get into the chronic pain management programs of two Montreal-based rehabilitation centres. Participants were also recruited from the community via support groups for people living with chronic pain and through flyers posted at medical centres. All participants provided informed consent prior to participating in the study. This study was approved by the research ethics board of the Centre for Interdisciplinary Research in Rehabilitation of Greater Montreal (CRIR).

\section{2 | Procedures}

Data from this study focus on the baseline testing session within a larger longitudinal study. Participants came to a research laboratory for a single baseline testing session that involved completion of self-report questionnaires (demographics, pain catastrophizing, pain-related fear, self-report activity avoidance, pain-related disability, depression and 
pain severity), followed by QST (pressure pain threshold and temporal summation of mechanical pain) and then brief physical performance tasks (functional measure of activity avoidance). This testing session took approximately $3-4 \mathrm{hr}$ to complete and included some additional functional tasks (e.g., repeated lifting, range of motion and strength testing) that were not the focus of the present analysis. Details of the specific measures used in this study are described below.

\section{3 $\mid$ Measures}

Measures are grouped within the following 4 categories that correspond to our data analytic approach: (a) the psychological predictors of the FAM, (b) pain sensitivity measured by QST, (c) FAM-related outcomes and (d) covariates.

\subsection{1 | The psychological predictors of the FAM}

\section{Pain catastrophizing}

The Pain Catastrophizing Scale (PCS) was used to measure the level of pain-related catastrophic thinking. The PCS is a 13-item self-report questionnaire, where each item is rated on a 5-point Likert scale with endpoints (0) not at all and (4) all the time (Sullivan, Bishop, \& Pivik, 1995). The PCS asks participants to indicate the degree to which they experienced each of 13 thoughts and feelings listed in the scale.

3 PCS produces a total score and three sub-scores based on assessment of the three elements rumination, magnification and helplessness. The total score of PCS was used in this analysis. Higher scores indicate greater catastrophic thoughts. The PCS is a widely used measure of pain catastrophizing that has been shown to have strong reliability and validity (Osman et al., 2000, 1997; Sullivan et al., 1995; Walton, Wideman, \& Sullivan, 2013).

\section{Pain-related fear}

The 11-item version of the Tampa Scale of Kinesiophobia (TSK) was used to measure pain-related fear. Previous research suggests that the term "kinesiophobia" is likely a misnomer for the items included in this scale (Lundberg, Grimby-Ekman, Verbunt, \& Simmonds, 2011; Pincus, Smeets, Simmonds, \& Sullivan, 2010; Wideman et al., 2013). Rather than phobic responses, this scale measures beliefs associated with fears of re-injury, physical activity and pain-related tissue damage (Kronshage, Kroener-Herwig, \& Pfingsten, 2001; Leonhardt et al., 2009; Lundberg et al., 2011). This scale uses a 4-point scale in which higher scores indicate greater pain-related fear (Hapidou et al.., 2012). Aside from the ambiguity associated with its name, the TSK has been consistently shown to have strong internal consistency, test-retest reliability (Walton \& Elliott, 2013) and predictive value when used to evaluate FAM predictions among people chronic musculoskeletal pain conditions (Lamé, Peters, Kessels, Kleef, \& Patijn, 2008; Roelofs, Goubert, Peters, Vlaeyen, \& Crombez, 2004; Swinkels-Meewisse, Swinkels, Verbeek, Vlaeyen, \& Oostendorp, 2003; Woby, Roach, Urmston, \& Watson, 2005).

\subsection{2 | QST measures of pain sensitivity}

This study included two previously validated QST measures of pain as follows: pressure pain threshold (PPT) and temporal summation of mechanical pain (TSP) (Goodin et al., 2014; Kavchak et al., 2012; Maier et al., 2010; Marcuzzi, Wrigley, Dean, Graham, \& Hush, 2018; Neziri et al., 2012; Walton, MacDermid, Nielson, Teasell, Reese et al., 2011). PPT is commonly regarded as an indirect, generalized measure of nervous system sensitivity, while TSP is commonly used as an indirect, psychophysical proxy for central sensitization (Binderup et al., 2010; Coronado, Riddle, Wurtzel, \& George, 2011; Staud, Weyl, Riley, Fillingim, \& Fillingim, 2014; You, Creech, \& Meagher, 2016).

\section{Pressure pain threshold (PPT)}

PPT is defined as the point at which blunt pressure of increasing intensity is first perceived as painful. Lower PPT readings indicate higher pain sensitivity. A digital algometer with a $1 \mathrm{~cm}^{2}$ hard rubber probe (Wagner instruments, CT) was used to measure the PPT following standardized procedures (Brennum, Kjeldsen, Jensen, \& Staehelin Jensen, 1989). To help ensure a comprehensive assessment of pain sensitivity across the body, PPT was evaluated at 8 different sites, including both hands (web space between the first and second digits), the bilateral low back ( $5 \mathrm{~cm}$ lateral to the $3 \mathrm{rd}$ lumbar vertebrae), the bilateral upper back $(5 \mathrm{~cm}$ lateral to the first thoracic vertebrae) and both calves (upper $1 / 3 \mathrm{rd}$ of muscle belly). Consistent with previous approaches, 3 trials were conducted at each site with a 30-s break in between each trial, and values (kilopascals) were averaged across trials (Walton, MacDermid, Nielson, Teasell, Chiasson et al., 2011; Walton, MacDermid, Nielson, Teasell, Reese et al., 2011; Wideman et al., 2014).

\section{Temporal summation of mechanical pain (TSP)}

TSP was measured by evaluating changes in pain ratings in response to repeated pinprick stimuli. Consistent with previous work, pinprick stimuli were administered using weighted punctate probes that were fitted with a small $(0.2 \mathrm{~mm}$ diameter), but flat tip, making them safe for non-invasive use (MRC Systems, Germany; Rolke, Magerl et al., 2006). Punctate probes with 32, 64, 128 and $256 \mathrm{mN}$ weights were used. Consistent with previous approaches, participants first received a single stimulus from each of the probes to determine which probe would be used to administer repeated supra-threshold stimuli. The lightest punctate probe to elicit a pain rating of at least 20/100 
(numeric rating scale that ranged from 0 , no pain, to 100 , worst pain imaginable) was selected for repeated use (Edwards et al., 2016; Wideman et al., 2014). This probe was then used to deliver 10 repeated stimuli at a rate of one stimulus per second. A metronome was used to ensure the stimuli were precisely timed. Immediately following the ten stimuli, participants were asked to rate their peak pain during the procedure. TSP values were calculated by subtracting the pain rating from the single stimulus from the peak pain during the repeated stimuli (Campbell et al., 2016; Edwards et al., 2011, 2013). Higher TSP values indicate greater pain sensitivity. Similar to our approach to PPT assessment, TSP was evaluated at 8 different sites across the body: the dorsal aspect of the middle fingers, the bilateral low back $(5 \mathrm{~cm}$ lateral to the $3 \mathrm{rd}$ lumbar vertebrae), the bilateral upper back ( $5 \mathrm{~cm}$ lateral to the first thoracic vertebrae) and both calves (upper 1/3rd of muscle belly).

\subsection{3 | FAM-related outcomes}

\section{Activity avoidance}

This study used two measures that were designed to quantify the FAM's activity avoidance construct, one self-report and one based on functional performance. The physical interference subscale of the Brief Pain Inventory (BPI) was used as the self-report measure (Walton, Putos, Beattie, \& MacDermid, 2016). The BPI is a widely used and recommended scale with strong reliability and validity among people with persistent pain (Dworkin et al., 2005; Osborne, Raichle, Jensen, Ehde, \& Kraft, 2006; Walton et al., 2016). Consistent with past work, the physical interference subscale was calculated from BPI items relating to how pain interferes with engagement in general activity, walking and normal work-related activities (Walton et al., 2016). The physical interference subscale was seen as a useful proxy for the FAM-related activity avoidance construct as its items are designed to specifically quantify pain-related barriers to activity engagement. The three items in this subscale are specifically designed to quantify the degree to which pain interferes with activity engagement. Items are rated on an 11-point numerical rating scale (0-10), in which higher scores indicate greater disruption to activity engagement due to pain.

A brief lifting tolerance task was used as the functional measure of activity avoidance. Consistent with previous work, this task involved lifting and holding a $3.9 \mathrm{~kg}$ canister with a single, fully extended arm, with the back in slightly forward bent posture (Lambin, Thibault, Simmonds, Lariviere, \& Sullivan, 2011; Sullivan, Larivire, \& Simmonds, 2010; Sullivan, Thibault et al., 2009; Sullivan et al., 2006). Participants were asked to hold the weighted canister for as long as possible. The duration of the sustained lift (recorded in seconds) was used as an index of activity avoidance, in which less time indicates greater avoidance. Previous research has used this, and related tasks, as indices of activity avoidance (Lambin et al., 2011; Martin, Rief, Klaiberg, $\&$ Braehler, 2006; Sullivan et al., 2006; Vlaeyen, Kole-Snijders,
Boeren et al., 1995). This functional measure of activity avoidance is closely related to the functional measures of activity avoidance used in other FAM-related research (Lindström et al., 1992; Vlaeyen, Kole-Snijders, Boeren et al., 1995; Vlaeyen, Kole-Snijders, Rotteveel et al., 1995).

\section{Depression}

The Patient Health Questionnaire-9 (PHQ-9) was used to evaluate depressive symptoms. This 9-item self-report questionnaire asks respondents to rate how often they have been bothered by specific problems in the past 2 weeks. A 4-point scale is used ranging from not at all (0) to nearly every day (3). The PHQ-9 has shown to be a valid and reliable tool for measuring depressive severity (Kroenke \& Spitzer, 2002; Martin et al., 2006).

\section{Pain-related disability}

The Pain Disability Index (PDI) was used as a self-report measure of pain-related disability. The PDI includes seven domains of daily living including home, social, recreational, occupational, sexual, self-care and life support. Participants rated their disability on an 11-point scale ranging from no disability (0) to total disability (10). The PDI is a reliable and valid tool for measuring pain-related disability (Tait, Chibnall, \& Krause, 1990). It has been used in numerous studies relating to the FAM and considered as a general measure of disability (Zale, Lange, Fields, \& Ditre, 2013).

\section{Pain severity}

The 4-item pain severity subscale of the Brief Pain Inventory (BPI) was used to measure the FAM construct of pain. The four items asked participants to rate their present pain as well as their worst, least and average pain over the prior 24-hr period. Each item was rated on an 11-point (0-10) numerical rating scale of pain intensity, in which 0 indicates "no pain" and 10 means "pain as bad as you can imagine". The BPI pain severity subscale is calculated as mean of the four items (Leonhardt et al., 2009). The BPI has been validated and recommended for measuring pain severity among people with non-cancer pain conditions (Dworkin et al., 2005; Keller et al., 2004).

\subsection{4 $\mid$ Covariates}

Consistent with previous research (Hergenroeder, Wert, Hile, Studenski, \& Brach, 2011; Thumboo, Chew, \& Lewin-Koh, 2002; Uddin et al., 2016; Uddin, Macdermid et al., 2014), covariates were designed to capture socio-demographic attributes commonly associated with pain and physical function and included gender, ethnicity, number of comorbidities and body mass index (BMI). Gender (coded as man/woman), ethnicity (coded as Caucasian/non-Caucasian) and comorbidities were assessed by asking participants to self-identify additional health conditions from a list of 24 conditions. 
TA B L E 1 Characteristics of the study sample

\begin{tabular}{|c|c|}
\hline Characteristics & Mean \pm SD or $N(\%)$ \\
\hline Age & $53.14 \pm 13.27$ \\
\hline \multicolumn{2}{|l|}{ Gender } \\
\hline Women & $57(71.3 \%)$ \\
\hline Man & $23(28.8 \%)$ \\
\hline \multicolumn{2}{|l|}{ Ethnicity } \\
\hline Caucasian & $66(82.5 \%)$ \\
\hline $\begin{array}{l}\text { Other (African, Latino, Middle- } \\
\text { Eastern, Unknown) }\end{array}$ & $14(18.5 \%)$ \\
\hline Body mass index & $29.10 \pm 6.76$ \\
\hline Comorbidity count & $1.58 \pm 1.13$ \\
\hline \multicolumn{2}{|l|}{ Language } \\
\hline French & $43(53.8 \%)$ \\
\hline English & $37(46.3 \%)$ \\
\hline \multicolumn{2}{|l|}{ Relationship status } \\
\hline Single (unmarried, divorced, widowed) & $52(65 \%)$ \\
\hline Partner (married, common-law) & $28(35 \%)$ \\
\hline \multicolumn{2}{|l|}{ Education level } \\
\hline School & $29(36.3 \%)$ \\
\hline College & $19(23.8 \%)$ \\
\hline Bachelor & $18(22.5 \%)$ \\
\hline Professional & $10(12.5 \%)$ \\
\hline Postgraduate (masters or doctorate) & $4(5 \%)$ \\
\hline $\begin{array}{l}\text { Pain duration in years (since pain onset } \\
\text { to test date) }\end{array}$ & $10.67 \pm 11.65$ \\
\hline $\begin{array}{l}\text { Number of painful body sites }(0-7)^{\mathrm{a}} \text {, } \\
\text { mean }(S D)\end{array}$ & $4.96 \pm 2.01$ \\
\hline \multicolumn{2}{|l|}{ Distribution of painful body sites, $n(\%)$} \\
\hline Right upper extremity ${ }^{a}$ & $78(67.2 \%)$ \\
\hline Left upper extremity ${ }^{\mathrm{a}}$ & $75(64.7 \%)$ \\
\hline Right lower extremity ${ }^{a}$ & $91(78.4 \%)$ \\
\hline Left lower extremity $^{\mathrm{a}}$ & $90(77.6 \%)$ \\
\hline Front trunk $\mathrm{k}^{\mathrm{a}}$ & $71(61.2 \%)$ \\
\hline Back $^{\mathrm{a}}$ & $103(88.8 \%)$ \\
\hline Head, face and/or neck ${ }^{\mathrm{a}}$ & $73(62.9 \%)$ \\
\hline
\end{tabular}

Notes. Values based on pooled completed data $(N=80)$, except variables with superscript "a" which are based on individuals $(N=115)$ who met the inclusion criteria and agreed to participate.

$S D$ : standard deviation.

BMI was calculated based on height and weight measures recorded during the testing session.

\section{4 | Approach to data analysis}

Analyses were performed using IBM SPSS Statistics for Windows, Version 24.0 (IBM Corp., Armonk, NY, USA). Descriptive analyses of the sample were generated and reported in the appropriate metrics for all variables of this study. Cases with incomplete data were removed by filtering. Significant levels were set at 0.05 alpha level for analyses. Histograms were used inspect the distribution of individual variable, and normality tests (i.e., KolmogorovSmirnov and Shapiro-Wilks) were performed prior to hypothesis testing.

Data analysis was conducted in two main steps. First, bivariate Pearson's correlational analysis was used to evaluate the univariate relationships between potential study predictors (psychological factors, QST measures of pain sensitivity and covariates) and FAM-related outcomes. Second, variables that were significantly $(p<0.05)$ associated with outcomes were integrated within a series of hierarchical regression analyses that evaluated whether indices of pain sensitivity contributed unique predictive value beyond significant psychological factors and covariates. In order to avoid biasing the predictive value of different independent variables in this study and consistent with previous work in this area (Gay, Horn, Bishop, Robinson, \& Bialosky, 2015), data analysis was conducted on participants that had complete data on all of the independent and dependent variables of interest.

Consistent with previous research (Freeman et al., 2014; Greenspan et al., $201=$ Vallin et al., 2012), a series of prin-4 45 cipal components analyses (PCA) were used to collapse data associated with PPT and TSP measures across different body sites. PCAs were used to limit the effects of multi-collin- $\mathbf{6}$ earity caused by potentially high correlations between QST measures from different body sites. Separate PCAs were conducted (as needed) for each regression analysis. Each PCA involved a two-step process. The first step consisted of determining which of the body sites for each measure (PPT or TSP) were significantly correlated with the FAM-related outcome of interest. The second step consisted of entering these statistically significant body sites into a PCA (PPT and TSP measures were entered into separate PCAs given that they map onto different constructs of sensitivity). The resultant factors were then entered into the regression analysis. PCAs were only conducted if more than one body site was significantly correlated with the outcome of interest. This two-step approach to PCA is consistent with literature that highlights the statistical advantages of first using a correlation matrix to identify predictors of interest, before entering these variables into a PCA (Jolliffe \& Cadima, 2016). This data analytic approach also aligned with the broader model-driven statistical analysis used with the other predictors of interest in this study.

\section{3 | RESULTS}

\section{1 | Selection of the study sample}

One hundred eighty-five people expressed interest in the study and received additional information about participation. Of 
these individuals, 116 met the inclusion criteria and agreed to participate. Of these individuals, 80 participants completed all measures included in this study. Between groups, $t$ tests comparing participants with complete versus those with incomplete data were non-significant for all variables. Only complete data (from participants who completed all measures) were retained for analysis. Thus, the study sample consisted of 80 adults ( 23 men and 57 women).

\subsection{Characteristics of the study sample}

Table 1 presents the characteristics of the study sample. To summarize, the mean age of the sample was 53.14 years and the majority of participants were women $(71.3 \%$ of the sample). More than $80 \%$ participants self-identified a Caucasian. On average, participants lived with pain for more than a decade (10.67 years). The mean number of comorbidities was $1.58 \pm 1.13$. The most common comorbid conditions that were identified by study participants included (frequency in parenthesis) depression (34), diabetes (12), spinal stenosis (11), osteoporosis (6), cancer (6) and neuropathies (3). Based on mean BMI (29.10), participants, on average, were classified as overweight (Gorber, Tremblay, Moher, \& Gorber, 2007). On average, participants identified (from the body diagram on the BPI) that their pain was distributed across $4.96 \pm 2.01$ number of body sites (out of defined seven body sites).

Table 2 provides median, means and standard deviations for the psychological predictors, QST measures of pain sensitivity and FAM-related outcomes. The mean pain severity score (5.63) suggests an overall moderate level of pain intensity across the sample (Boonstra et al., 2016). Scores on the PCS (mean $=27.25$ and median $=27$ ) and TSK $($ mean $=30.53$ and median $=30)$ were broadly consistent with the scores of other study samples that have been used to evaluate different aspects of the FAM (e.g., Larsson et al., 2016; Wideman, Adams, \& Sullivan, 2009; Wideman \& 7 Sullivan, 2012).

T A B L E 2 Mean and standard deviations for primary predictors and outcomes $(N=80)$

\begin{tabular}{|c|c|c|c|c|}
\hline Constructs & Variables & Measures & Mean $\pm S D$ & Median \\
\hline $\begin{array}{l}\text { Psychological predictors of } \\
\text { FAM }\end{array}$ & Pain-related fear & Tampa Scale of Kinesiophobia & $30.53 \pm 9.18$ & 30.00 \\
\hline \multirow{12}{*}{$\begin{array}{l}\text { QST measures of pain } \\
\text { sensitivity }\end{array}$} & \multirow[t]{5}{*}{ Pressure pain thresholds } & PPT_RH & $184.89 \pm 111.33$ & 156.80 \\
\hline & & PPT_RUB & $203.62 \pm 117.97$ & 178.30 \\
\hline & & PPT_LUB & $198.93 \pm 136.60$ & 187.57 \\
\hline & & PPT_RLB & $214.43 \pm 156.59$ & 164.21 \\
\hline & & PPT_LLB & $214.93 \pm 155.15$ & 164.96 \\
\hline & \multirow{7}{*}{$\begin{array}{l}\text { Temporal summation of mechani- } \\
\text { cal pain }\end{array}$} & TSP_LH & $22.72 \pm 21.48$ & 20.00 \\
\hline & & TSP_RUB & $17.59 \pm 20.62$ & 10.00 \\
\hline & & TSP_LUB & $22.81 \pm 20.98$ & 20.00 \\
\hline & & TSP_RLB & $27.33 \pm 25.85$ & 21.00 \\
\hline & & TSP_LLB & $29.24 \pm 22.44$ & 21.00 \\
\hline & & TSP_RC & $26.00 \pm 21.36$ & 21.50 \\
\hline & & TSP_LC & 28.53 & 25.00 \\
\hline \multirow[t]{2}{*}{ FAM-related outcomes } & Avoidance (self-report) & BPI physical interference & $6.10 \pm 2.19$ & 6.33 \\
\hline & Avoidance (functional) & Lift tolerance & $8.41 \pm 14.79$ & 4.00 \\
\hline
\end{tabular}

Note. BPI: Brief Pain Inventory; FAM: fear-avoidance model of pain; LC: left calf; LH: left hand; LLB: left lower back; LUB: left upper back; PHQ-9: Patient Health Questionnaire-9; PPT: pressure pain threshold; QST: quantitative sensory testing; RC: right calf; RH: right hand; RLB: right lower back; RUB: right upper back; TSP: temporal summation of mechanical pain. 


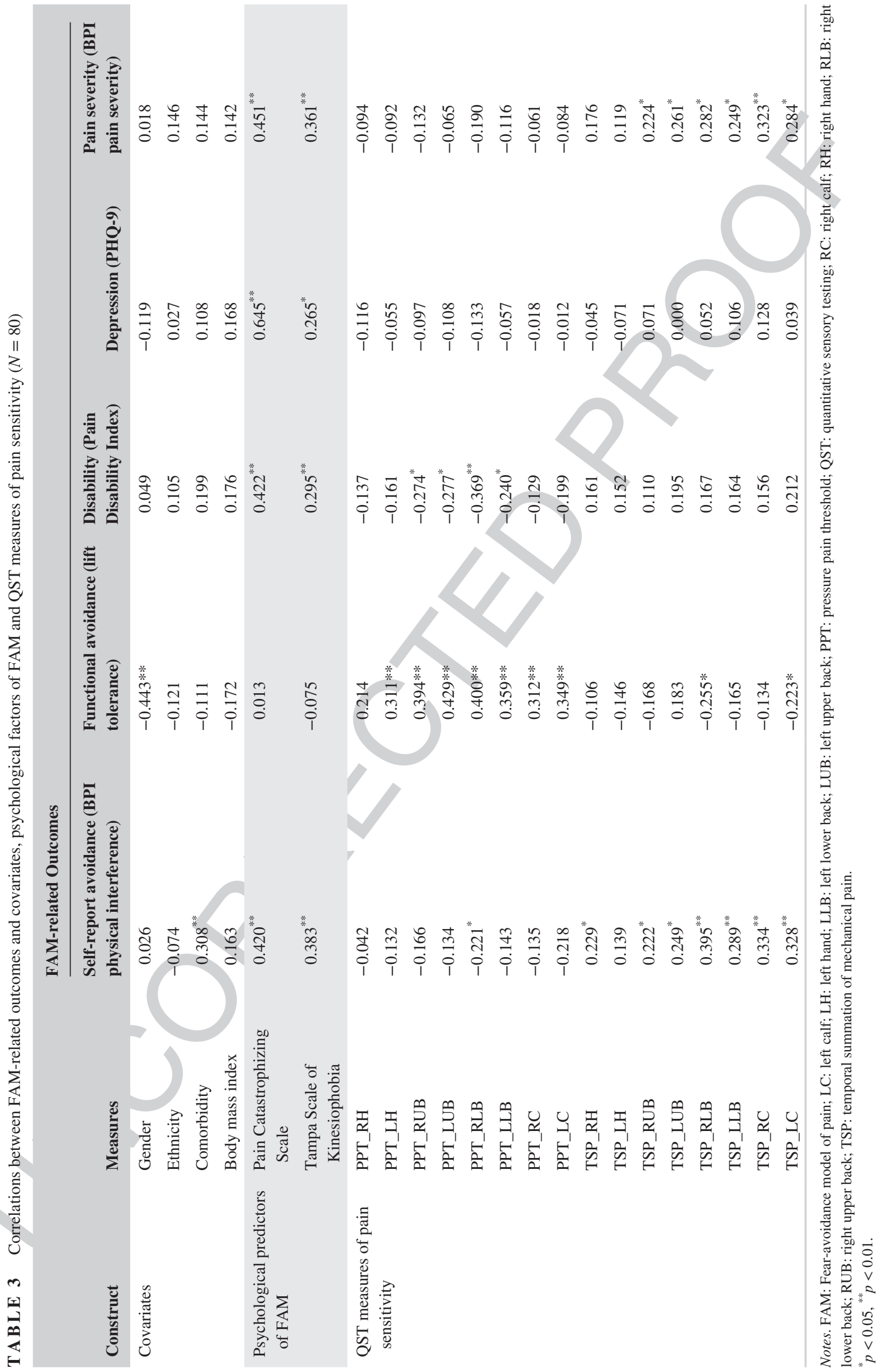




\section{3 | Univariate relationships}

Table 3 shows correlations between all independent variables and FAM-related outcomes. To summarize, self-reported avoidance was significantly correlated with number of comorbidities, both psychological predictors, one PPT and seven TSP measures. Functional avoidance was significantly correlated with gender, seven PPT measures and two TSP measures, but was not significantly related to either of the psychological predictors. Pain-related disability was significantly correlated with both psychological predictors and four PPT measures, but was not significantly related to any of the TSP measures. Depression was significantly correlated with both of the psychological predictors, but none of the QST measures of pain sensitivity. Pain severity was significantly correlated with both of the psychological predictors and six of the TSP measures, but was not significantly related to any of the PPT measures.

\section{4 | Correlations among QST measures of pain sensitivity}

Table 4 shows correlations between all QST measures of pain sensitivity. All measures of PPT were significantly correlated with one another, and all measures of TSP were also significantly correlated with one another. QST variables met all assumptions for PCA (Field, 2013; Jolliffe, 1986).

\subsection{Hierarchical regression analyses predicting each of the FAM-related outcomes}

Table 5 shows the final models of each of the regression analyses.

\subsection{1 | Predicting self-reported avoidance}

Number of comorbidities, pain catastrophizing and pain-related fear variables were entered in step 1 of a hierarchical regression analysis, and the TSP factor (PCA of seven significant TSP variables) and the single PPT variable were entered in step 2. In the final model, the TSP factor was shown to significantly contribute an additional $9.3 \%$ variance beyond the psychological factors $(\beta=0.252, t=2.613, p<0.01)$. Both of the psychological factors remained significant predictors in the final model, while the single PPT measure was not a significant predictor.

\subsection{2 | Predicting functional avoidance}

Gender was entered in step 1 of a hierarchical regression analysis. When entered in step 2, the PPT factor (PCA of seven PPT variables) was shown to be a significant predictor $(\beta=0.249$, $t=2.281, p<0.05$ ), while the TSP factor (PCA of two TSP variables) failed to contribute significant variance. In the final model, the PPT factor was shown to significantly contribute an additional $8.1 \%$ variance beyond the psychological factors.

\subsection{3 | Predicting disability}

Psychological variables were entered in step 1, and the PPT factor (PCA of four PPT variables) was entered in step 2. The PPT factor was a significant predictor $(\beta=-0.321$, $t=-3.335, p<0.01)$ and explained an additional $10.2 \%$ of variance beyond the psychological predictors, which also remained significant in the final model.

\subsection{4 | Predicting depression}

Only pain catastrophizing and pain-related fear variables were entered into the regression model. When entered together, only pain catastrophizing significantly predicted depression $(\beta=0.626, t=6.786, p<0.01)$.

\subsection{5 $\mid$ Predicting pain severity}

Psychological factors were entered in step 1, and the TSP factor (PCA of six TSP variables) was entered in step 2. The TSP factor was a significant predictor of pain severity $(\beta=0.248, t=2.576, p<0.01)$ and explained an additional $6 \%$ in the variance beyond psychological factors, which also remained significant in the final regression model.

\section{4 | DISCUSSION}

These findings help extend the emerging evidence exploring the role of pain sensitivity within the FAM. Consistent with FAM predictions and past research, our study indicates that pain catastrophizing and pain-related fear predict several pain-related outcomes, including self-report measures of avoidance, disability, depression and pain severity (Leeuw et al., 2007; Meulders, Vansteenwegen, \& Vlaeyen, 2011; Vlaeyen, Kole-Snijders, Boeren et al., 1995; Vlaeyen, Kole-Snijders, Rotteveel et al., 1995; Vlaeyen \& Linton, 2000, 2012; Vlaeyen \& Morley, 2005; Wideman et al., 2009). However, our findings also show that indices of pain sensitivity offer unique predictive value to FAM-related outcomes even after controlling for these psychological factors. QST measures of pain sensitivity contributed unique predictive variance to four of the five FAM outcomes evaluated in this study; depression was the only outcome not significantly predicted by pain sensitivity. In the final regression models, TSP measures were shown to predict self-report avoidance and pain severity, while PPT measures predicted functional avoidance and self-report disability. Interestingly, when it 


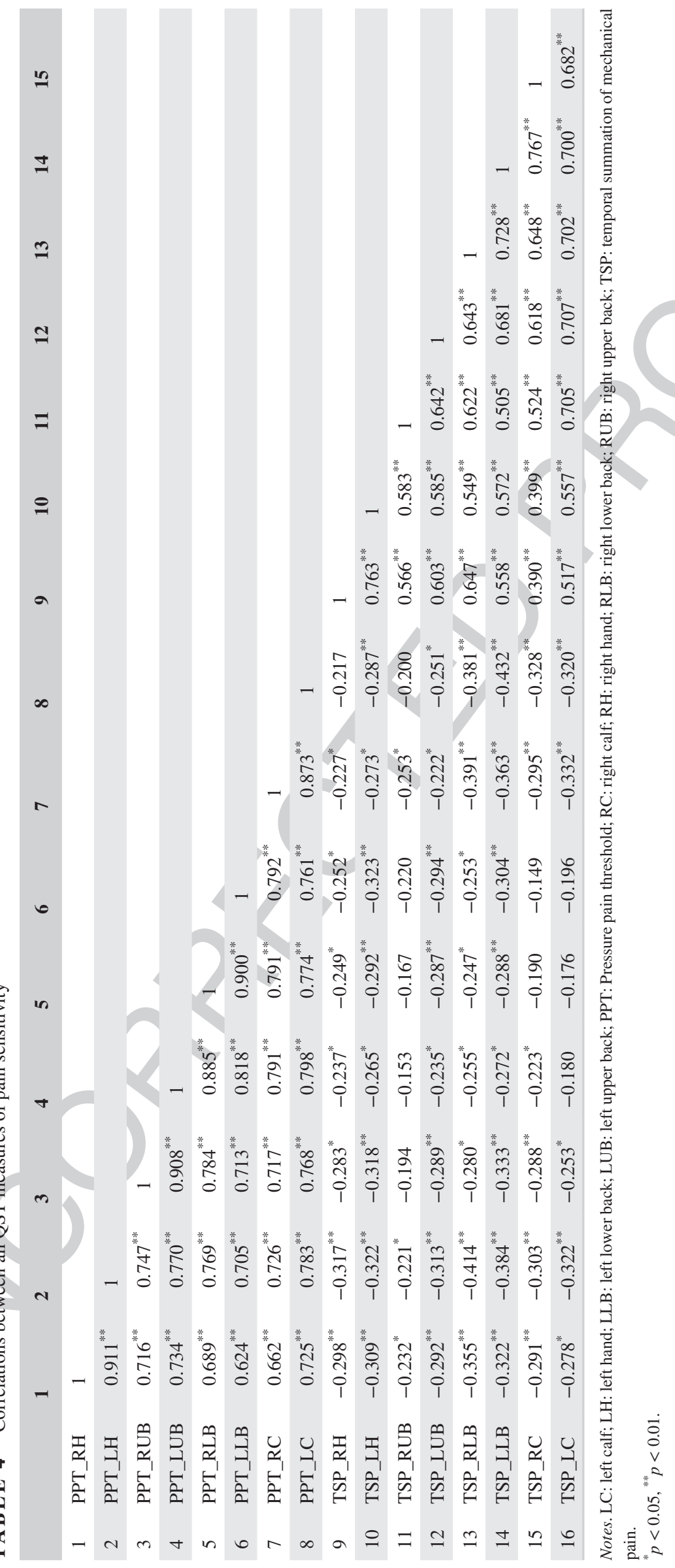


TA B LE 5 Hierarchical regression analyses predicting FAM-related outcomes $(N=80)$

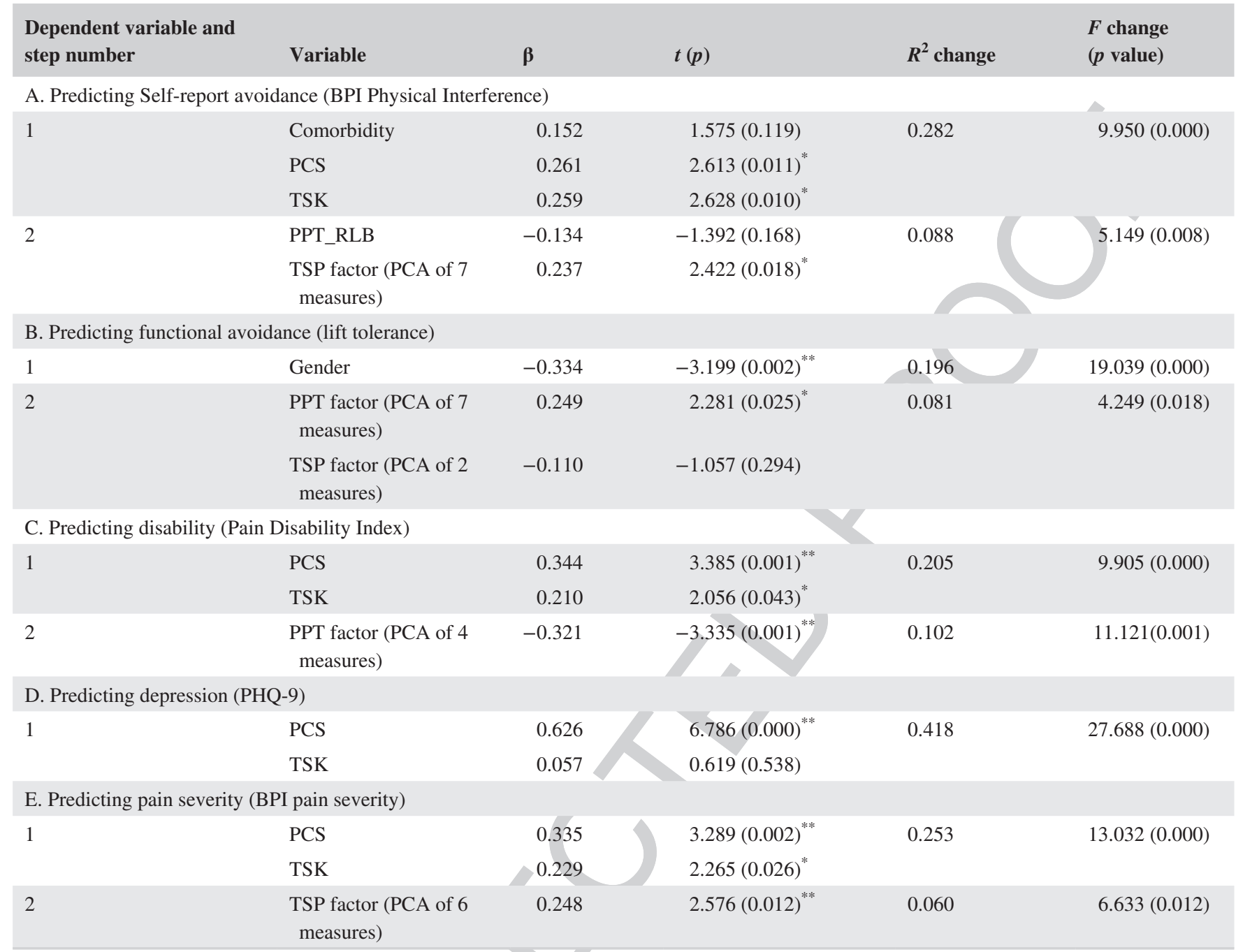

Notes. All $\beta$ and $t$ values from the final regression model.

BPI: Brief Pain Inventory; PCA: principal components analysis; PCS: Pain Catastrophizing Scale; PHQ-9: Patient Health Questionnaire-9; PPT: pressure pain threshold; RLB: right lower back; TSK: Tampa Scale of Kinesiophobia; TSP: temporal summation of mechanical pain. ${ }^{*} p<0.05,{ }^{* *} p<0.01$.

came to predicting the non-self-report measure in our study, measures of pain sensitivity, but not the FAM-related psychological factors, contributed significant variance. These findings add further support for the predictive value of pain sensitivity within the FAM and have important clinical and theoretical implications that are discussed below.

Our findings build on two previous studies that specifically compared the predictive value of FAM-related psychological factors (i.e., pain catastrophizing and pain-related fear) to QST measures of pain sensitivity in determining FAM-related outcomes. Our findings are broadly consistent with those of Pedler et al (Pedler, Kamper, \& Sterling, 2016) who conducted a longitudinal study among people with whiplash injuries. Using a mixed-model analysis, their study showed that two measures of pain threshold (PPT and cold pain threshold) predicted self-report measures of pain and disability beyond FAM-related psychological factors.
Our findings extend this work by linking different QST measures of pain sensitivity (including a psychophysical measure of central sensitization) to a broader range of FAM-related outcomes (including functional and self-report measures of avoidance) and help generalize these findings within an additional clinical population (chronic widespread pain).

A second study conducted by Gay et al. (2015) reported that a QST measure of temporal summation of pain failed to directly predict self-reported disability beyond FAM psychological factors. This specific finding is actually consistent with ours, in that in our study, only measures of PPT, but not TSP, were associated with the pain-related disability outcome. These results point to an interesting pattern of findings within our study in which specific measures of pain sensitivity appear to be mapping onto specific FAM-related outcomes. For instance, our study regression analyses showed that only measures of PPT predicted disability and functional 
avoidance outcomes, while only measures of TSP predicted self-report avoidance and pain severity outcomes. With some exceptions, these relationships were largely consistent within our univariate correlational analyses. It is hard to compare this pattern of findings to other work in this area as neither of these previous studies included both measures of TSP and PPT within their analyses (Gay et al., 2015; Pedler et al., 2018). If future research is able to replicate our findings, there may be important implications for using mechanismbased management strategies to target-specific FAM-related outcomes. For instance, previous work has highlighted that certain pain interventions have a unique effect on indices of central sensitization (Arendt-Nielsen et al., 1995, 2011; Eide, 2000; Harding, Kristensen, \& Baranowski, 2005), and these interventions may offer novel added value in targeting the FAM-related outcomes that are associated with indices of TSP.

Our study also revealed differential predictive relationships in relation to self-report and functional measures of avoidance. Within our study, FAM-related psychological factors predicted the self-report, but not the functional, measure of avoidance, while QST measures of pain sensitivity mapped onto both outcomes. These findings are broadly consistent with previous research that shows that FAM-related psychological factors are more robust predictors of self-report, rather than objective, measures of activity engagement (Bousema, Verbunt, Seelen, Vlaeyen, \& André Knottnerus, 2007; Lundberg et al., 2011; Pincus et al., 2010; Verbunt et al., 2001; Wideman et al., 2013). They are also consistent with emerging work that suggests that different measures of activity-related pain sensitivity contribute unique predictive value, beyond psychological factors, in explaining physical performance outcomes (Lambin et al., 2011; Sullivan, 2008; Sullivan et al., 2010; Sullivan, Thibault et al., 2009; Wideman, Edwards, Finan, Haythornthwaite, \& Smith, 2016; Wideman et al., 2014; Wideman \& Sullivan, 2012). This research broadly highlights the importance of considering both self-report and functional outcomes in this line of work and the unique predictive value of evoked measures of pain sensitivity in determining functional outcomes.

In our analysis, depression was the only outcome not predicted by QST measures of pain sensitivity. This is broadly consistent with previous work that has explored the relationship between evoked measures of pain sensitivity and depressive symptoms (Schneider, Pogatzki-Zahn, Marziniak, Stumpf, \& Ständer, 2015). Together these findings suggest that, perhaps unsurprisingly, depressive symptoms correspond more closely to the emotional, rather than sensory, dimensions of pain.

These findings help contribute to the growing clinical and theoretical literature addressing the FAM. First, these findings add further empirical support to previous calls for integrating neurophysiological factors and processes within the primarily cognitive-behavioural FAM (Pedler et al., 2018, 2016; Wideman et al., 2013). From a clinical perspective, our findings suggest that including measures of pain sensitivity may help improve the prognostic accuracy and contribute to optimization of clinical services. Nijs, Houdenhove, \& Oostendorp (2010) have proposed clinical guidelines for determining whether patients with musculoskeletal pain should be classified as having elevated pain sensitivity and which may help facilitate the clinical application of these findings. These findings also hold potential for better matching theoretically driven interventions to patient profiles. For example, one of the leading FAM-driven treatments for patients that have elevated catastrophic thoughts and pain-related fear are graded exposure interventions. These treatments focus on reducing the threat value of physical activity by facilitating systematic re-engagement in feared movements, while largely downplaying or ignoring pain severity (George, Fritz, Bialosky, \& Donald, 2003; George, Wittmer, Fillingim, \& Robinson, 2010; George \& Zeppieri, 2009; Vlaeyen, Jong, Geilen, Heuts, \& Breukelen, 2001; Vlaeyen, Morley, Linton, Boersma, \& Jong, 2012). Our findings, however, suggest pain sensitivity is a driver of activity engagement and that this treatment approach may be problematic among people with elevated neurophysiological pain sensitivity. For these individuals, repeated exposure to painful movements may actually further sensitize their nervous system and potentially contribute to further avoidance. Future research should $\mathbf{8}$ focus on evaluating these potentially problematic responses by comparing the effects of these interventions between sub-groups of patients that only have elevated psychological factors with those that also have elevated levels of nervous system pain sensitivity. There is also a need for future research that explores novel approaches to clinical management that specifically addresses both cognitive-behavioural and sensory dimensions of pain.

Important limitations should be considered when interpreting the findings from our study. First, this study used a cross-sectional cohort design, which limits generalization of its findings. Additional prospective studies that evaluate the predictive value of pain sensitivity within the FAM are needed. Second, it is important to remember that the QST assessment used in this study are psychophysical, rather than physiological, measures. Like all psychophysical measures, QST can be influenced by a wide range of biopsychosocial factors and should not be regarding as uniquely associated with the neurophysiological processes underlying pain. Third, it should also be pointed out there is conceptual ambiguity in how our self-report activity interference should be related to the constructs of the FAM. While we believe that items from this measure have good face validity with the FAM construct of activity avoidance, there is also potential conceptual overlap with the construct of disability. Further research is needed to best 
determine how to align versus differentiate these measures and constructs.

Despite these limitations, these findings help advance the literature in this area. Our findings provide further evidence for the importance of neurophysiological factors within the FAM by showing the novel added value of QST measures even after controlling model-relevant predictors. This study extends previous work in this area by validating these relationships among patients with chronic widespread pain and using a comprehensive approach to measuring both pain sensitivity and FAM-related outcomes. This methodology helped shed light on the differential predictive value of dynamic (TSP) versus static (PPT) measures of pain sensitivity as well as the unique value of evoked measures (and the potential limitations of psychological factors) in predicting functional measures of avoidance. Our findings also highlight the need for future research that explores whether evoked measures of pain sensitivity may have added value, in addition to psychological factors, in guiding risk stratified management strategies that potentially combine both cognitive-behavioural and sensory-based interventions.

\section{ACKNOWLEDGMENTS}

This study was generously supported by the following organizations: Centre de recherche interdisciplinaire en réadaptation du Montréal métropolitain, Constance-Lethbridge Rehabilitation Centre, Centre de réadaptation LucieBruneau, Louise and Alan Edwards Foundation, Quebec Pain Research Network, Canadian Musculoskeletal Rehab Research Network, Institut de recherche Robert-Sauvé en santé et en sécurité du travail (IRSST) and the Canadian Institutes for Health Research.

\section{CONFLICT OF INTEREST}

None declared.

\section{REFERENCES}

910 Apkarian, A. V., Baliki, M. N., \& Geha, P. Y. (2009). Towards a theory of chronic pain. Progress in Neurobiology, 87, 81-97. https://doi. org/10.1016/j.pneurobio.2008.09.018

Arendt-Nielsen, L., Petersen-Felix, S., Fischer, M., Bak, P., Bjerring, P., \& Zbinden, A. M. (1995). The effect of N-methyl-D-aspartate antagonist (ketamine) on single and repeated nociceptive stimuli: A placebo-controlled experimental human study. Anesthesia and Analgesia, 81, 63-68.

Arendt-Nielsen, L., \& Yarnitsky, D. (2009). Experimental and clinical applications of quantitative sensory testing applied to skin, muscles and viscera. The Journal of Pain, 10, 556-572. https://doi. org/10.1016/j.jpain.2009.02.002

Arendt-Nielsen, L., Mansikka, H., Staahl, C., Rees, H., Tan, K., Smart, T. S., ... Drewes, A. M. (2011). A translational study of the effects of ketamine and pregabalin on temporal summation of experimental Pain. Regional Anesthesia and Pain Medicine, 36, 585-591. https:// doi.org/10.1097/AAP.0b013e31822b0db0

Binderup, A. T., Arendt-Nielsen, L., \& Madeleine, P. (2010). Pressure pain sensitivity maps of the neck-shoulder and the low back regions in men and women. BMC Musculoskeletal Disorders, 11, 234. https://doi.org/10.1186/1471-2474-11-234

Bishop, M. D., Horn, M. E., \& George, S. Z. (2011). Exercise-induced pain intensity predicted by pre-exercise fear of pain and pain sensitivity. Clinical Journal of Pain, 27, 398-404. https://doi. org/10.1097/AJP.0b013e31820d9bbf

Boonstra, A. M., Stewart, R. E., Köke, A. J. A., Oosterwijk, R. F. A., Swaan, J. L., Schreurs, K. M. G., \& Schiphorst Preuper, H. R. (2016). Cut-off points for mild, moderate, and severe pain on the numeric rating scale for pain in patients with chronic musculoskeletal pain: Variability and influence of sex and catastrophizing. Frontiers in Psychology, 7, 1466. https://doi.org/10.3389/fpsyg.2016.01466

Bousema, E. J., Verbunt, J. A., Seelen, H. A. M., Vlaeyen, J. W. S., \& André Knottnerus, J. (2007). Disuse and physical deconditioning in the first year after the onset of back pain. Pain, 130, 279-286. https://doi.org/10.1016/j.pain.2007.03.024

Brennum, J., Kjeldsen, M., Jensen, K., \& Staehelin Jensen, T. (1989). Measurements of human pressure-pain thresholds on fingers and toes. Pain, 38, 211-217. https://doi.org/10.1016/0304-3959(89)90240-6

Campbell, C. M., Moscou-Jackson, G., Carroll, C. P., Kiley, K., Haywood, C., Lanzkron, S., ... Haythornthwaite, J. A. (2016). An evaluation of central sensitization in patients with sickle cell disease. The Journal of Pain, 17, 617-627. https://doi.org/10.1016/j. jpain.2016.01.475

Coronado, R. A., Riddle, D. L., Wurtzel, W. A., \& George, S. Z. (2011). Bibliometric analysis of articles published from 1980 to 2009 in physical therapy, Journal of the American Physical Therapy Association. Physical Therapy, 91, 642-655. https://doi. org/10.2522/ptj.20100267

Crombez, G., Eccleston, C., Van Damme, S., Vlaeyen, J. W. S., \& Karoly, P. (2012). Fear-avoidance model of chronic pain. Clinical Journal of Pain, 28, 475-483. https://doi.org/10.1097/AJP.0b013e3182385392

Dworkin, R. H., Turk, D. C., Farrar, J. T., Haythornthwaite, J. A., Jensen, M. P., Katz, N. P., ... Witter, J. (2005). Topical review and recommendations Core outcome measures for chronic pain clinical trials: IMMPACT recommendations. Pain, 113, 9-19. https://doi. org/10.1016/j.pain.2004.09.012

Edwards, R. R., Wasan, A. D., Michna, E., Greenbaum, S., Ross, E., \& Jamison, R. N. (2011). Elevated pain sensitivity in chronic pain patients at risk for opioid misuse. The Journal of Pain, 12, 953-963. https://doi.org/10.1016/j.jpain.2011.02.357

Edwards, R. R., Dolman, A. J., Michna, E., Katz, J. N., Nedeljkovic, S. S., Janfaza, D., ... Wasan, A. D. (2016). Changes in pain sensitivity and pain modulation during oral opioid treatment: The impact of negative affect. Pain Medicine, 17, 1882-1891. https://doi. org/10.1093/pm/pnw010

Edwards, R. R., Mensing, G., Cahalan, C., Greenbaum, S., Narang, S., Belfer, I., ... Jamison, R. N. (2013). Alteration in pain modulation in women with persistent post- lumpectomy pain: Influence of catastrophizing. Journal of Pain and Symptom Management, 46, 30-42.

Eide, P. K. (2000). Wind-up and the NMDA receptor complex from a clinical perspective. European Journal of Pain, 4, 5-15. https://doi. org/10.1053/eujp.1999.0154

Field, A. (2013). Discovering statistics using IBM SPSS Statistics. Sage.11 
Finan, P. H., Buenaver, L. F., Bounds, S. C., Hussain, S., Park, R. J., Haque, U. J., ... Smith, M. T. (2013). Discordance between pain and radiographic severity in knee osteoarthritis: Findings from quantitative sensory testing of central sensitization. Arthritis and Rheumatism, 65, 363-372. https://doi.org/10.1002/art.34646

Gay, C. W., Horn, M. E., Bishop, M. D., Robinson, M. E., \& Bialosky, J. E. (2015). Investigating dynamic pain sensitivity in the context of the fear-avoidance model. European Journal of Pain, 19, 48-58. https://doi.org/10.1002/ejp.519

George, S. Z., Fritz, J. M., Bialosky, J. E., \& Donald, D. A.. (2003). The effect of a fear-avoidance-based physical therapy intervention for patients with acute low back pain: Results of a randomized clinical trial. Spine, 28, 2551-2560.

George, S. Z., Wittmer, V. T., Fillingim, R. B., \& Robinson, M. E. (2010). Comparison of graded exercise and graded exposure clinical outcomes for patients with chronic low back pain. Journal of Orthopaedic and Sports Physical Therapy, 40, 694-704. https://doi. org/10.2519/jospt.2010.3396

George, S. Z., \& Zeppieri, G. (2009). Physical therapy utilization of graded exposure for patients with low back pain. Journal of Orthopaedic \& Sports Physical Therapy, 39, 496-505. https://doi. org/10.2519/jospt.2009.2983

Goodin, B. R., Bulls, H. W., Herbert, M. S., Schmidt, J., King, C. D., Glover, T. L., ... Fillingim, R. B. (2014). Temporal summation of pain as a prospective predictor of clinical pain severity in adults aged 45 years and older with knee osteoarthritis: Ethnic differences. Psychosomatic Medicine, 76, 302-310. https://doi.org/10.1097/ PSY.0000000000000058

Gorber, S. C., Tremblay, M., Moher, D., \& Gorber, B. (2007). A comparison of direct vs. self-report measures for assessing height, weight and body mass index: A systematic review. Obesity Reviews, 8, 307-326. https://doi.org/10.1111/j.1467-789X.2007.00347.x

Graven-Nielsen, T., \& Arendt-Nielsen, L. (2010). Assessment of mechanisms in localized and widespread musculoskeletal pain. Nature Reviews Rheumatology, 6, 599-606. https://doi.org/10.1038/nrrheum.2010.107

Hapidou, E. G., O’Brien, M. A., Pierrynowski, M. R., de las Heras, E., Patel, M., \& Patla, T. (2012). Fear and avoidance of movement in people with chronic pain: Psychometric properties of the 11-item Tampa scale for Kinesiophobia (TSK-11). Physiother Canada, 64, 235-241. https://doi.org/10.3138/ptc.2011-10

Harding, L. M., Kristensen, J. D., \& Baranowski, A.P. (2005). Differential effects of neuropathic analgesics on wind-up-like pain and somatosensory function in healthy volunteers. Clinical Journal of Pain, 21, 127-132. https://doi.org/10.1097/00002508-200503000-00003

Hergenroeder, A. L., Wert, D. M., Hile, E. S., Studenski, S. A., \& Brach, J. S. (2011). Association of Body Mass Index with self-report and performance-based measures of balance and mobility. Physical Therapy, 91, 1223-1234. https://doi.org/10.2522/ptj.20100214

Hübscher, M., Moloney, N., Leaver, A., Rebbeck, T., Mcauley, J. H., \& Refshauge, K. M. (2013). Comprehensive review relationship between quantitative sensory testing and pain or disability in people with spinal pain-A systematic review and meta-analysis. Pain, 154, 1497-1504. https://doi.org/10.1016/j.pain.2013.05.031

Jolliffe, I. T. (1986). Principal component analysis and factor analysis (pp. 115-128). New York, NY: Springer.

Jolliffe, I. T., \& Cadima, J. (2016). Principal component analysis: A review and recent developments. Philosophical Transactions of the Royal Society A: Mathematical, Physical and Engineering Sciences, 374, 20150202. https://doi.org/10.1098/rsta.2015.0202
Kavchak, A. J. E., Fernández-de-las-Peñas, C., Rubin, L. H., ArendtNielsen, L., Chmell, S. J., Durr, R. K., \& Courtney, C. A. (2012). Association between altered somatosensation, pain, and knee stability in patients with severe knee osteoarthrosis. The Clinical Journal oF Pain, 28, 589-594. https://doi.org/10.1097/AJP.0b013e31823ae18f

Keller, S., Bann, C. M., Dodd, S. L., Schein, J., Mendoza, T. R., \& Cleeland, C. S. (2004). Validity of the brief pain inventory for use in documenting the outcomes of patients with noncancer pain. Clinical Journal of Pain, 20, 309-318. https://doi. org/10.1097/00002508-200409000-00005

Kroenke, K., \& Spitzer, R. L. (2002). The PHQ-9: A new depression diagnostic and severity measure. Psychiatric Annals, 32, 509-515. https://doi.org/10.3928/0048-5713-20020901-06

Kronshage, U., Kroener-Herwig, B., \& Pfingsten, M. (2001). Kinesiophobia in chronic low back pain patients-Does the startle paradigm support the hypothesis? International Journal of Behavioral Medicine, 8, 304-318.

Kroska, E. B. (2016). A meta-analysis of fear-avoidance and pain intensity: The paradox of chronic pain. Scandinavian Journal of Pain, 13, 43-58. https://doi.org/10.1016/j.sjpain.2016.06.011

Lambin, D. I., Thibault, P., Simmonds, M., Lariviere, C., \& Sullivan, M. J. L. (2011). Repetition-induced activity-related summation of pain in patients with fibromyalgia. Pain, 152, 1424-1430. https:// doi.org/10.1016/j.pain.2011.02.030

Lamé, I. E., Peters, M. L., Kessels, A. G., Van Kleef, M., \& Patijn, J. (2008). Test-retest stability of the pain catastrophizing scale and the Tampa Scale for Kinesiophobia in chronic pain patients over a longer period of time. Journal of Health Psychology, 13, 820-826.

Leeuw, M., Goossens, M. E. J. B., Linton, S. J., Crombez, G., Boersma, K., \& Vlaeyen, J. W. S. (2007). The fear-avoidance model of musculoskeletal pain: Current state of scientific evidence. Journal of Behavioral Medicine, 30, 77-94. https://doi.org/10.1007/ s10865-006-9085-0

Leonhardt, C., Lehr, D., Chenot, J. F., Keller, S., Luckmann, J., Basler, H. D., ... Becker, A. (2009). Are fear-avoidance beliefs in low back pain patients a risk factor for low physical activity or vice versa? A cross-lagged panel analysis. Psycho-social Medicine, 6, Doc01.

Lim, E. C. W., Sterling, M., Stone, A., \& Vicenzino, B. (2011). Central hyperexcitability as measured with nociceptive flexor reflex threshold in chronic musculoskeletal pain: A systematic review. Pain, 152, 1811-1820. https://doi.org/10.1016/j.pain.2011.03.033

Lindström, I., Ohlund, C., Eek, C., Wallin, L., Peterson, L. E., Fordyce, W. E., \& Nachemson, A. L. (1992). The effect of graded activity on patients with subacute low back pain: A randomized prospective clinical study with an operant-conditioning behavioral approach. Physical Therapy, 72, 279-290; discussion 291-3. https://doi. org/10.1093/ptj/72.4.279

Lundberg, M., Grimby-Ekman, A., Verbunt, J., \& Simmonds, M. J. (2011). Pain-related fear: A critical review of the related measures. Pain Research and Treatment, 2011, 1-26. https://doi. org/10.1155/2011/494196

Maier, C., Baron, R., Tölle, T. R., Binder, A., Birbaumer, N., Birklein, F., ... Treede, D.-R. (2010). Quantitative sensory testing in the German Research Network on Neuropathic Pain (DFNS): Somatosensory abnormalities in 1236 patients with different neuropathic pain syndromes. Pain, 150, 439-450. https://doi.org/10.1016/j. pain.2010.05.002

Maixner, W., Fillingim, R., Sigurdsson, A., Kincaid, S., \& Silva, S. (1998). Sensitivity of patients with painful temporomandibular 
disorders to experimentally evoked pain: Evidence for altered temporal summation of pain. Pain, 76, 71-81. https://doi.org/10.1016/ S0304-3959(98)00028-1

Mallen, C. D., Peat, G., Thomas, E., Dunn, K. M., \& Croft, P. R. (2007). Prognostic factors for musculoskeletal pain in primary care: A systematic review. British Journal of General Practice, 57, 655-661.

Marcuzzi, A., Wrigley, P. J., Dean, C. M., Graham, P. L., \& Hush, J. M. (2018). From acute to persistent low back pain: A longitudinal investigation of somatosensory changes using quantitative sensory testing-an exploratory study. Pain Reports, 3, e641. https://doi. org/10.1097/PR9.0000000000000641

Martin, A., Rief, W., Klaiberg, A., \& Braehler, E. (2006). Validity of the Brief Patient Health Questionnaire Mood Scale (PHQ-9) in the general population. General Hospital Psychiatry, 28, 71-77. https:// doi.org/10.1016/j.genhosppsych.2005.07.003

Mason, K. J., O’Neill, T. W., Lunt, M., Jones, A. K. P., \& McBeth, J. (2018). Psychosocial factors partially mediate the relationship between mechanical hyperalgesia and self-reported pain. Scandinavian Journal of Pain, 18, 59-69. https://doi.org/10.1515/ sjpain-2017-0109

Matos, R., Wang, K., Jensen, J. D., Jensen, T., Neuman, B., Svensson, P., \& Arendt-Nielsen, L. (2011). Quantitative sensory testing in the trigeminal region: Site and gender differences. Journal of Orofacial Pain, 25, 161-169.

Meulders, A., Vansteenwegen, D., \& Vlaeyen, J. W. S. (2011). The acquisition of fear of movement-related pain and associative learning: A novel pain-relevant human fear conditioning paradigm. Pain, 152, 2460-2469. https://doi.org/10.1016/j.pain.2011.05.015

Neziri, A. Y., Curatolo, M., Limacher, A., Nüesch, E., Radanov, B., Andersen, O. K., ... Jüni, P. (2012). Ranking of parameters of pain hypersensitivity according to their discriminative ability in chronic low back pain. Pain, 153, 2083-2091. https://doi.org/10.1016/j. pain.2012.06.025

Nijs, J., Van Houdenhove, B., \& Oostendorp, R. A. B. (2010). Recognition of central sensitization in patients with musculoskeletal pain: Application of pain neurophysiology in manual therapy practice. Manual Therapy, 15, 135-141. https://doi.org/10.1016/j. math.2009.12.001

Osborne, T.L., Raichle, K. A., Jensen, M. P., \& Ehde,D. M., Kraft, G. (2006). The reliability and validity of pain interference measures in persons with multiple sclerosis. Journal of Pain and Symptom Management, 32, 217-229. https://doi.org/10.1016/j.jpainsymman.2006.03.008

Osman, A., Barrios, F. X., Gutierrez, P. M., Kopper, B. A., Merrifield, T., \& Grittmann, L. (2000). The Pain Catastrophizing Scale: Further psychometric evaluation with adult samples. Journal of Behavioral Medicine, 23, 351-365.

Osman, A., Barrios, F. X., Kopper, B. A., Hauptmann, W., Jones, J., \& O’Neill, E. (1997). Factor structure, reliability, and validity of the pain catastrophizing scale. Journal of Behavioral Medicine, 20, $589-605$

Parr, J. J., Borsa, P. A., Fillingim, R. B., Tillman, M. D., Manini, T. M., Gregory, C. M., \& George, S. Z. (2012). Pain-related fear and catastrophizing predict pain intensity and disability independently using an induced muscle injury model. The Journal of Pain, 13, 370-378. https://doi.org/10.1016/j.jpain.2011.12.011

Pedler, A., Kamper, S. J., Maujean, A., \& Sterling, M. (2018). Investigating the fear avoidance model in people with whiplash the association between fear of movement and in vivo activity. Clinical Journal of Pain, 34, 130-137.
Pedler, A., Kamper, S. J., \& Sterling, M. (2016). Addition of posttraumatic stress and sensory hypersensitivity more accurately estimates disability and pain than fear avoidance measures alone after whiplash injury. Pain, 157, 1645-1654. https://doi.org/10.1097/j. pain.0000000000000564

Pincus, T., Smeets, R. J. E. M., Simmonds, M. J., \& Sullivan, M. J. L. (2010). The fear avoidance model disentangled: Improving the clinical utility of the fear avoidance model. Clinical Journal of Pain, 26, 739-746. https://doi.org/10.1097/AJP.0b013e3181f15d45

Roelofs, J., Goubert, L., Peters, M. L., Vlaeyen, J. W. S., \& Crombez, G. (2004). The Tampa Scale for Kinesiophobia: Further examination of psychometric properties in patients with chronic low back pain and fibromyalgia. European Journal of Pain, 8, 495-502. https:// doi.org/10.1016/j.ejpain.2003.11.016

Rolke, R., Baron, R., Maier, C., Tölle, T. R., Treede, D. R., Beyer, A., ... Wasserka, B. (2006). Quantitative sensory testing in the German Research Network on Neuropathic Pain (DFNS): Standardized protocol and reference values. Pain, 123, 231-243.

Rolke, R., Magerl, W., Campbell, K. A., Schalber, C., Caspari, S., Birklein, F., \& Treede, R. D. (2006). Quantitative sensory testing: A comprehensive protocol for clinical trials. European Journal of Pain, 10, 77-88.

Schneider, G., Pogatzki-Zahn, E., Marziniak, M., Stumpf, A., \& Ständer, S. (2015). Cutaneous sensory function is not related to depression and anxiety in patients with chronic pruritus with dysesthetic subqualities. Acta Dermato Venereologica, 95, 289-293. https://doi. org/10.2340/00015555-1933

Staud, R., Robinson, M. E., \& Price, D. D. (2007). Temporal summation of second pain and its maintenance are useful for characterizing widespread central sensitization of fibromyalgia patients. The Journal of Pain, 8, 893-901. https://doi.org/10.1016/j. jpain.2007.06.006

Staud, R., Weyl, E. E., Riley, J. L., Fillingim, R. B., \& Fillingim, R. B. (2014). Slow temporal summation of pain for assessment of central pain sensitivity and clinical pain of fibromyalgia patients. PLoS One, 9, e89086. https://doi.org/10.1371/journal. pone. 0089086

Sullivan, M. J. L. (2008). Toward a biopsychomotor conceptualisation of pain: Implications for Research and Intervention. Clinical Journal of Pain, 24, 281-290.

Sullivan, M. J. L. L., Bishop, S. R., \& Pivik, J. (1995). The Pain Catastrophizing Scale: Development and validation. Psychological Assessment, 7, 524-532. https://doi.org/10.1037/1040-3590.7.4.524

Sullivan, M. J. L., Larivire, C., \& Simmonds, M. (2010). Activity-related summation of pain and functional disability in patients with whiplash injuries. Pain, 151, 440-446. https://doi.org/10.1016/j. pain.2010.08.005

Sullivan, M., Tanzer, M., Stanish, W., Fallaha, M., Keefe, F. J., Simmonds, M., \& Dunbar, M. (2009). Psychological determinants of problematic outcomes following Total Knee Arthroplasty. Pain, 143, 123-129.

Sullivan, M. J. L., Thibault, P., Andrikonyte, J., Butler, H., Catchlove, R., \& Larivière, C. (2009). Psychological influences on repetitioninduced summation of activity-related pain in patients with chronic low back pain. Pain, 141, 70-78.

Sullivan, M. J. L. L., Thibault, P., Savard, A., Catchlove, R., Kozey, J., \& Stanish, W. D. (2006). The influence of communication goals and physical demands on different dimensions of pain behavior. Pain, 125, 270-277. https://doi.org/10.1016/j.pain.2006.06.019 
Swinkels-Meewisse, E. J. C. M., Swinkels, R. A. H. M., Verbeek, A. L. M., Vlaeyen, J. W. S., \& Oostendorp, R. A. B. (2003). Psychometric properties of the Tampa Scale for kinesiophobia and the fear-avoidance beliefs questionnaire in acute low back pain. Manual Therapy, 8, 29-36. https://doi.org/10.1054/ math.2002.0484

Tait, R. C., Chibnall, J. T., \& Krause, S. (1990). The Pain Disability Index: Psychometric properties. Pain, 40, 171-182. https://doi. org/10.1016/0304-3959(90)90068-O

Tampin, B., Slater, H., Hall, T., Lee, G., \& Kathryn, N. (2012). Quantitative sensory testing somatosensory profiles in patients with cervical radiculopathy are distinct from those in patients with nonspecific neck - Arm pain. Pain, 153, 2403-2414. https://doi. org/10.1016/j.pain.2012.08.007

Thumboo, J., Chew, L.-H., \& Lewin-Koh, S.-C. (2002). Socioeconomic and psychosocial factors influence pain or physical function in Asian patients with knee or hip osteoarthritis. Annals of the Rheumatic Diseases, 61, 1017-1020. https://doi.org/10.1136/ard.61.11.1017

Uddin, Z., \& MacDermid, J. C. (2016). Quantitative sensory testing in chronic musculoskeletal pain. Pain Medicine, 17, 1694-1703. https://doi.org/10.1093/pm/pnv105

Uddin, Z., MacDermid, J. C., Galea, V., Gross, A. R., \& Pierrynowski, M. R. (2014). The current perception threshold test differentiates categories of mechanical neck disorder. The Journal of Orthopaedic and Sports Physical Therapy, 44, 532-C1.

Uddin, Z., MacDermid, J. C., Moro, J., Galea, V., \& Gross, A. R. (2016). Psychophysical and patient factors as determinants of pain, function and health status in shoulder disorders. The Open Orthopaedics Journal, 10, 466-480. https://doi. org/10.2174/1874325001610010466

Uddin, Z., Macdermid, J. C., Woodhouse, L. J., Triano, J. J., Galea, V., \& Gross, A. R. (2014). The effect of pressure pain sensitivity and patient factors on self- reported pain-disability in patients with chronic neck pain. The Open Orthopaedics Journal, 8, 302-309.

Vardeh, D., Mannion, R. J., \& Woolf, C. J. (2016). Toward a mechanism-based approach to pain diagnosis. The Journal of Pain, 17, T50-T69. https://doi.org/10.1016/j.jpain.2016.03.001

Verbunt, J. A., Westerterp, K. R., Van Der Heijden, G. J., Seelen, H. A., Vlaeyen, J. W., \& Knottnerus, J. A. (2001). Physical activity in daily life in patients with chronic low back pain. Archives of Physical Medicine and Rehabilitation, 82, 726-730. https://doi.org/10.1053/ apmr.2001.23182

Vlaeyen, J. W. S., De Jong, J., Geilen, M., Heuts, P. H. T. G., \& Van Breukelen, G. (2001). Graded exposure in vivo in the treatment of pain-related fear: A replicated single-case experimental design in four patients with chronic low back pain. Behavior Research and Therapy, 39, 151-166. https://doi.org/10.1016/S0005-7967(99)00174-6

Vlaeyen, J. W., Kole-Snijders, A. M., Boeren, R. G., \& van Eek, H. (1995). Fear of movement/(re)injury in chronic low back pain and its relation to behavioral performance. Pain, 62, 363-372.

Vlaeyen, J. W. S., Kole-Snijders, A. M. J., Rotteveel, A. M., Ruesink, R., \& Heuts, P. (1995). The role of fear of movement (re)injury in pain disability. Journal of Occupational Rehabilitation, 5, 235-252.

Vlaeyen, J. W. S., \& Linton, S. J. (2000). Fear-avoidance and its consequences in chronic musculoskeletal pain: A state of the art. Pain, 85, 317-332. https://doi.org/10.1016/S0304-3959(99)00242-0

Vlaeyen, J. W. S., \& Linton, S. J. (2012). Fear-avoidance model of chronic musculoskeletal pain: 12 years on. Pain, 153, 1144-1147. https://doi.org/10.1016/j.pain.2011.12.009
Vlaeyen, J. W. S., \& Morley, S. (2005). Cognitive-behavioral treatments for chronic pain: What works for whom? Clinical Journal of Pain, $21,1-8$.

Vlaeyen, J. W., Morley, S., Linton, S., Boersma, K., \& De Jong, J. (2012). Pain-related fear: Exposure-based treatment for chronic pain. Journal of Palliative Medicine, 16, 1158-1159.

Wallin, M., Liedberg, G., Börsbo, B., \& Gerdle, B. (2012). Thermal detection and pain thresholds but not pressure pain thresholds are correlated with psychological factors in women with chronic whiplash-associated pain. Clinical Journal of Pain, 28, 211-221. https:// doi.org/10.1097/AJP.0b013e318226c3fd

Walton, D., \& Elliott, J. M. (2013). A higher-order analysis supports use of the 11-item version of the Tampa Scale for kinesiophobia in people with neck pain. Physical Therapy, 93, 60-68. https://doi. org/10.2522/ptj.20120255

Walton, D., MacDermid, J., Nielson, W., Teasell, R., Chiasson, M., \& Brown, L. (2011). Reliability, standard error, and minimum detectable change of clinical pressure pain threshold testing in people with and without acute neck pain. The Journal of Orthopaedic and Sports Physical Therapy, 41, 644-650.

Walton, D., MacDermid, J., Nielson, W., Teasell, R., Reese, H., \& Levesque, L. (2011). Pressure pain threshold testing demonstrates predictive ability in people with acute whiplash. The Journal of Orthopaedic and Sports Physical Therapy, 41, 658-665.

Walton, D. M., Putos, J., Beattie, T., \& MacDermid, J. C. (2016). Confirmatory factor analysis of 2 versions of the Brief Pain Inventory in an ambulatory population indicates that sleep interference should be interpreted separately. Scandinavian Journal of Pain, 12, 110-116. https://doi.org/10.1016/j.sjpain.2016.05.002

Walton, D. M., Wideman, T. H., \& Sullivan, M. J. L. (2013). A rasch analysis of the pain catastrophizing scale supports its use as an interval-level measure. Clinical Journal of Pain, 29, 499-506. https:// doi.org/10.1097/AJP.0b013e318269569c

Wideman, T. H., Adams, H., \& Sullivan, M. J. L. (2009). A prospective sequential analysis of the fear-avoidance model of pain. Pain, 145, 45-51. https://doi.org/10.1016/j.pain.2009.04.022

Wideman, T. H., Edwards, R. R., Finan, P. H., Haythornthwaite, J. A., \& Smith, M. T. (2016). Comparing the predictive value of task performance and task-specific sensitivity during physical function testing among people with knee osteoarthritis. The Journal of Orthopaedic and Sports Physical Therapy, 46, 346-356. https://doi.org/10.2519/ jospt.2016.6311

Wideman, T. H., Finan, P. H., Edwards, R. R., Quartana, P. J., Buenaver, L. F., Haythornthwaite, J. A., \& Smith, M. T. (2014). Increased sensitivity to physical activity among individuals with knee osteoarthritis: Relation to pain outcomes, psychological factors, and responses to quantitative sensory testing. Pain, 155, 703-711.

Wideman, T. H., \& Sullivan, M. J. L. (2012). Development of a cumulative psychosocial factor index for problematic recovery following work-related musculoskeletal injuries. Physical Therapy, 92, 58-68. https://doi.org/10.2522/ptj.20110071

Wideman, T. H., Asmundson, G. G. J., Smeets, R. J. E. M., Zautra, A. J., Simmonds, M. J., Sullivan, M. J. L., ... Edwards, R. R. (2013). Rethinking the fear avoidance model: Toward a multidimensional framework of pain-related disability. Pain, 154, 2262-2265. https:// doi.org/10.1016/j.pain.2013.06.005

Woby, S. R., Roach, N. K., Urmston, M., \& Watson, P. J. (2005). Psychometric properties of the TSK-11: A shortened version of the 
Tampa Scale for Kinesiophobia. Pain, 117, 137-144. https://doi. org/10.1016/j.pain.2005.05.029

Woolf, C. (2004). Pain: Moving from symptom control toward mechanism specific pharmacologic management. Annals of Internal Medicine, 140, 441-451. https://doi.org/10.7326/0003-4819-140-8200404200-00010

Woolf, C. J. (2011). Central sensitization: Implications for the diagnosis and treatment of pain. Pain 152, S2-S15. https://doi.org/10.1016/j. pain.2010.09.030

Woolf, C. J., \& Salter, M. W. (2000). Neuronal plasticity: Increasing the gain in pain. Science, 288, 1765-1768.

Yarnitsky, D., \& Granot, M. (2006). Chapter 27 Quantitative sensory

13 testing. In Handbook of clinical neurology (pp. 397-409). Elsevier.

You, D. S., Creech, S. K., \& Meagher, M. W. (2016). Enhanced area of secondary hyperalgesia in women with multiple stressful life events: A pilot study. Pain Medicine, 17, 1859-1864. https://doi. org/10.1093/pm/pnw049

Zale, E. L., Lange, K. L., Fields, S. A., \& Ditre, J. W. (2013). The relation between pain-related fear and disability: A meta-analysis. The Journal of Pain, 14, 1019-1030.

How to cite this article: Uddin Z, Woznowski-Vu A, Flegg D, Aternali A, Wickens R, Wideman TH.

Evaluating the novel added value of neurophysiological pain sensitivity within the fearavoidance model of pain. Eur J Pain. 2019;00:1-16. https://doi.org/10.1002/ejp.1364 